\title{
Petroselinic acid purification and its use for the fermentation of new sophorolipids
}

\author{
Elisabeth I. P. Delbeke', Jonas Everaert ${ }^{1,2}$, Evelien Uitterhaegen ${ }^{1,3}$, Stijn Verweire ${ }^{2}$, Arno Verlee' ${ }^{1}$, Thierry Talou ${ }^{3}$, \\ Wim Soetaert ${ }^{2}$, Inge N. A. Van Bogaert ${ }^{2}$ and Christian V. Stevens ${ }^{1 *}$
}

\begin{abstract}
Petroselinic acid, a positional isomer of oleic acid, was isolated from the vegetable oil of Coriandrum sativum fruits. This uncommon fatty acid was subsequently used as substrate for sophorolipid fermentation with a Starmerella bombicola lactone esterase overexpression (oe sble) strain. A petroselinic acid based diacetylated sophorolipid lactone was obtained in high purity without incorporation of de novo synthesized fatty acids such as oleic acid. A total production of $40 \mathrm{~g} / \mathrm{L}$ was obtained. The petroselinic acid based sophorolipid lactone was subsequently hydrolyzed towards the petroselinic acid based sophorolipid acid. For both compounds, their critical micelle concentration (CMC) and corresponding surface tension were compared to their oleic acid based counterparts. Both petroselinic acid based sophorolipids displayed a much lower CMC value than their oleic acid based counterparts, although their minimal surface tension was the same. Besides, the sophorolipid fermentation product was chemically modified towards a novel C12 sophorolipid aldehyde. This derivative constitutes an interesting building block for further modification towards new-to-nature sophorolipids with high potential for self-assembly applications.
\end{abstract}

Keywords: Petroselinic acid, Sophorolipid, Starmerella bombicola, Fermentation, Chemical derivatization

\section{Introduction}

Petroselinic acid $\mathbf{1}$ is a rather uncommon fatty acid (Scheme 1). With its double bond at the 6, 7-position, it is a positional isomer of oleic acid. The position of this double bond influences the properties of the fatty acid. For example, the melting point of petroselinic acid is $30{ }^{\circ} \mathrm{C}$, while the melting point of oleic acid is only $14{ }^{\circ} \mathrm{C}$ (Cahoon et al. 1994). Petroselinic acid is found in high amounts in the seed oils from plants belonging to the Apiaceae family, also known as Umbelliferae, and the Araliaceae family (Placek 1963). The quantity of petroselinic acid varies from 31 to $75 \%$ in the vegetable oil of fruits from Coriandrum sativum, one of the most enriched sources of petroselinic acid. This vegetable oil can be extracted from the fruits via twin-screw extrusion (Uitterhaegen et al. 2015). Petroselinic acid 1 is already applied in cosmetic formulations as a moisturizing and

\footnotetext{
*Correspondence: Chris.Stevens@UGent.be

1 SynBioC, Department of Sustainable Organic Chemistry and Technology, Ghent University, Coupure Links 653, 9000 Ghent, Belgium

Full list of author information is available at the end of the article
}

anti-aging agent, and as a skin-irritation reducing agent in $\alpha$-hydroxy acid containing compositions (Alaluf et al. 1999; Barrett et al. 2000; Weinkauf et al. 1998). Besides, a considerable antimicrobial activity against several bacteria, yeast and mold species was observed (Placek 1963). Several modifications of petroselinic acid $\mathbf{1}$ are described, among others towards surfactants and the nylon 66 precursor adipic acid (Cahoon et al. 1994; Dierker and Schafer 2010; Placek 1963). When incorporated in triglycerides, lipolysis by pancreatic lipase occurs at a much lower efficiency than for oleic acid triglycerides (Cahoon et al. 1994; Heimerma.Wh et al. 1973). Therefore, petroselinic acid rich oils may offer a low-fat alternative for conventional vegetable oils. It was also suggested that petroselinic acid inhibits the synthesis of arachidonic acid, which could counteract the vasoconstrictive effects related to arachidonic acid overproduction (Shukla and Gupta 2009; Weber et al. 1995).

Being a structural isomer of oleic acid, petroselinic acid could be applied for the synthesis of a new type of sophorolipid. These biosurfactants are produced by different yeast species, mainly Starmerella bombicola, from

\section{Springer Open}

(c) 2016 Delbeke et al. This article is distributed under the terms of the Creative Commons Attribution 4.0 International License (http://creativecommons.org/licenses/by/4.0/), which permits unrestricted use, distribution, and reproduction in any medium, provided you give appropriate credit to the original author(s) and the source, provide a link to the Creative Commons license, and indicate if changes were made. 


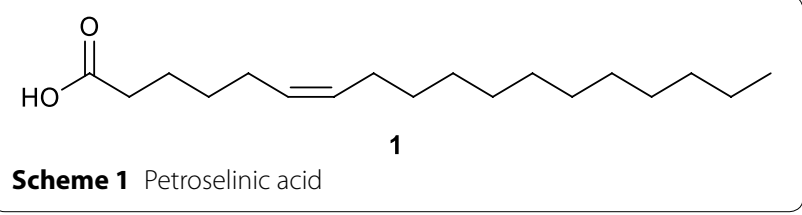

glucose as hydrophilic carbon source and a fatty acid as hydrophobic carbon source (Van Bogaert et al. 2007, 2011c). The main sophorolipid fermentation products are diacetylated C18:1 sophorolipid lactone 2 and C18:1 sophorolipid acid 3 which both include oleic acid in their structure (Scheme 2). Natural sophorolipids feature beneficial biological activities such as anti-cancer, antimicrobial, dermatological, immunoregulatory, spermicidal and antiviral activity (Delbeke et al. 2016; Morya et al. 2013). They also possess self-assembly properties, with a high variety in the type of nanostructures formed for different sophorolipid derivatives (Baccile et al. 2010, 2012, 2013; Cuvier et al. 2014, 2015). For example, C18:1 sophorolipid acid 3 forms micelles with the charge dependent on the $\mathrm{pH}$, while its saturated derivative forms nanoscale ribbons with supramolecular chirality (Cuvier et al. 2014).

As the properties for petroselinic acid differ considerably from those of oleic acid, it can be anticipated that petroselinic acid derived sophorolipids will possess different biological activities and self-assembly properties than the oleic acid based sophorolipids. Moreover, chemical derivatization of these petroselinic acid derived sophorolipids will result in new types of innovative sophorolipid derivatives. In this work, the purification of petroselinic acid 1 and its application for the synthesis of innovative sophorolipid derivatives is described (Scheme 3). First, petroselinic acid is purified from the vegetable oil of $C$. sativum fruits. The purified fatty acid is subsequently used as substrate for sophorolipid fermentation with $S$. bombicola. To obtain $100 \%$ diacetylated sophorolipid lactones, the $S$. bombicola lactone esterase overexpression strain (oe sble) is used. Finally, the petroselinic acid derived sophorolipid lactone $\mathbf{5}$ is modified towards a C12 sophorolipid aldehyde 4 via an ozonolysis reaction.

\section{Materials and methods Materials}

The vegetable oil of $C$. sativum fruits was isolated via twin-screw extrusion at LCA via a previously reported procedure (Uitterhaegen et al. 2015). Trimethylsulfonium hydroxide (TMSH), $t$-butyl methyl ether (TBME), hydrochloric acid $(\mathrm{HCl})$, hexane, sodium citrate tribasic dihydrate, ammonium chloride $\left(\mathrm{NH}_{4} \mathrm{Cl}\right)$, potassium phosphate monobasic $\left(\mathrm{KH}_{2} \mathrm{PO}_{4}\right)$, potassium phosphate dibasic $\left(\mathrm{K}_{2} \mathrm{HPO}_{4}\right)$, magnesium sulfate heptahydrate $\left(\mathrm{MgSO}_{4} \cdot 7 \mathrm{H}_{2} \mathrm{O}\right)$, calcium chloride dihydrate $\left(\mathrm{CaCl}_{2} \cdot 2 \mathrm{H}_{2} \mathrm{O}\right)$, sodium, 4-dimethylaminopyridine (DMAP), Sudan III and diethyl ether were purchased from Sigma-Aldrich (Belgium). Yeast extract was purchased from Difco (Belgium). Sodium hydroxide $(\mathrm{NaOH})$, dry methanol, acetic anhydride and sodium triacetoxyborohydride $\left[\mathrm{NaBH}(\mathrm{OAc})_{3}\right]$ were purchased from Acros Organics (Belgium). Magnesium sulfate $\left(\mathrm{MgSO}_{4}\right)$ and sodium bicarbonate $\left(\mathrm{NaHCO}_{3}\right)$ were purchased from Fisher Scientific (Belgium). Ethyl acetate and tetrahydrofuran (THF) were purchased from Chem-Lab (Belgium). Glucose monohydrate was purchased from Cargill (Belgium). Sodium chloride $(\mathrm{NaCl})$ was purchased from $\mathrm{Col}-$ ruyt (Belgium).

\section{Analytical and instrumental methods}

Commercially available products were used without further purification. Tetrahydrofuran (THF) was distilled from sodium. The ozonolysis reaction was performed with an Ozonia Triogen Model LAB2B laboratory ozone generator, connected to a Bronkhorst Flow-Bus E-7000 type mass flow meter to control the dry air inflow and an

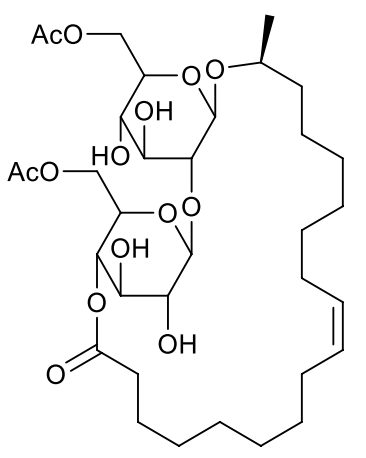

2

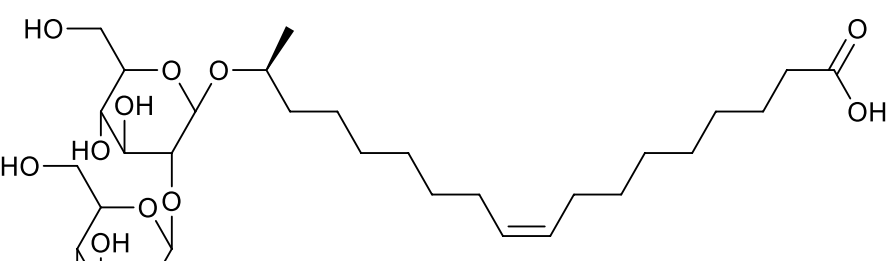

3

Scheme 2 Microbial produced sophorolipid lactone $\mathbf{2}$ and sophorolipid acid $\mathbf{3}$ 


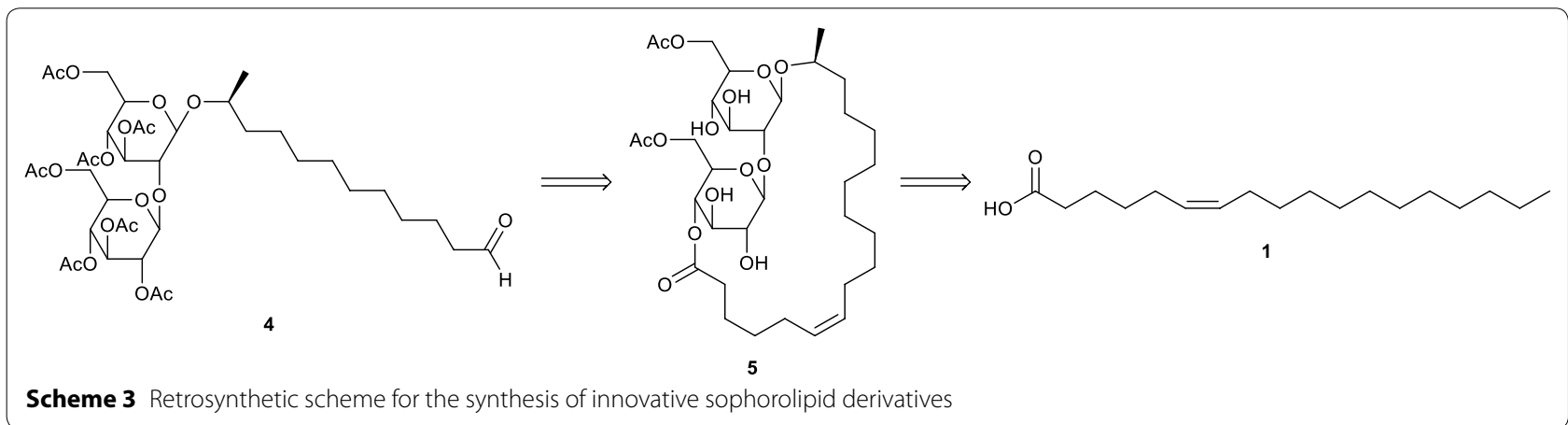

Anseros Ozomat Model GM Non-Dispersive UV-analyzer to measure the ozone concentration. NMR spectra were recorded at $400 \mathrm{MHz}\left({ }^{1} \mathrm{H}\right)$ and $100 \mathrm{MHz}\left({ }^{13} \mathrm{C}\right)$ in $\mathrm{CDCl}_{3}$ or $\mathrm{MeOD}$ with a Bruker Avance III Nanobay 400 $\mathrm{MHz}$ spectrometer at room temperature. Low-resolution mass spectra were recorded with a single quadrupole mass spectrometer (ESI, $70 \mathrm{eV}$ ). High-resolution mass spectra were obtained with a time-of-flight (TOF) mass spectrometer (ESI or APCI).

\section{Determination of the fatty acid composition of coriander oil}

Determination of the fatty acid composition of the coriander oil was performed by gas chromatography (GC). An oil sample was dissolved in TBME at a concentration of $20 \mathrm{mg} / \mathrm{mL}$. A $100 \mu \mathrm{L}$ aliquot of this solution was converted to methyl esters by the addition of $50 \mu \mathrm{L}$ of a 0.2 M TMSH solution in methanol. The resulting fatty acid methyl esters were subjected to GC analysis using a Varian 3800 (USA) gas chromatograph equipped with a flame ionization detector. Separation of the methyl esters was achieved in a CP select CB (Varian, USA) fused silica capillary column $(50 \mathrm{~m}, 0.25 \mathrm{~mm}$ i.d., $0.25 \mu \mathrm{m}$ film thickness). The initial oven temperature was held at $185^{\circ} \mathrm{C}$ for $40 \mathrm{~min}$, after which it was increased to $250^{\circ} \mathrm{C}$ for $10 \mathrm{~min}$. The temperature of the injector and the detector was kept at $250{ }^{\circ} \mathrm{C}$. Helium was used as the carrier gas with a flow rate of $1.2 \mathrm{~mL} / \mathrm{min}$. The determination was carried out in triplicate.

\section{General procedure for the isolation of petroselinic acid 1}

In a $2 \mathrm{~L}$ flask, $446.10 \mathrm{~g}$ of coriander oil is weighed and $800 \mathrm{~mL}$ of a $3 \mathrm{~N}$ sodium hydroxide solution is added. The reaction mixture is refluxed for $2.5 \mathrm{~h}$, cooled down and acidified to $\mathrm{pH} 1$ with a $3 \mathrm{~N}$ hydrochloric acid solution. The mixture is extracted with hexane and washed with water. The organic phase is dried over magnesium sulfate, filtered and concentrated under reduced pressure. Pure petroselinic acid is obtained through crystallization in absolute ethanol at $-20{ }^{\circ} \mathrm{C}$ as a white solid at room temperature (251.07 g, 80 \%) (Additional file 1: Figs. S1, S2).

\section{Culture conditions used for sophorolipid production}

A $S$. bombicola lactone esterase overexpression strain (oe sble, derived from S. bombicola ATCC 22214 and covered under the patent application WO 2013/092421) was used for the selective synthesis of diacetylated sophorolipid lactone 5 (Roelants et al. 2015; Van Bogaert et al. 2011a). The $S$. bombicola oe sble strain was cultivated on Lang medium (132 g/L glucose monohydrate; $4 \mathrm{~g} / \mathrm{L}$ yeast extract; $5 \mathrm{~g} / \mathrm{L}$ sodium citrate tribasic dihydrate; $1.5 \mathrm{~g} / \mathrm{L} \mathrm{NH}_{4} \mathrm{Cl} ; 1 \mathrm{~g} / \mathrm{L}$ $\mathrm{KH}_{2} \mathrm{PO}_{4} ; 0.16 \mathrm{~g} / \mathrm{L} \mathrm{K}_{2} \mathrm{HPO}_{4} ; 0.7 \mathrm{~g} / \mathrm{L} \mathrm{MgSO}_{4} \cdot 7 \mathrm{H}_{2} \mathrm{O} ; 0.5 \mathrm{~g} / \mathrm{L}$ $\mathrm{NaCl} ; 0.27 \mathrm{~g} / \mathrm{L} \mathrm{CaCl}_{2} \cdot 2 \mathrm{H}_{2} \mathrm{O}$ ) in a Biostat ${ }^{\circledR} \mathrm{B} 3 \mathrm{~L}$ culture vessel (Sartorius-BBI Systems) with a working volume of 1.1 L. Temperature $\left(30^{\circ} \mathrm{C}\right), \mathrm{pH}(3.5)$, stirring rate, and air flow rate $(1.5 \mathrm{~L} / \mathrm{min})$ were controlled by the Biostat ${ }^{\circledR} \mathrm{B}$ control unit (Lang et al. 2000). $100 \mathrm{~mL}$ of $30 \mathrm{~h}$ old shake flask cultures was used for inoculation of the culture vessel. $20 \mathrm{~g}$ of petroselinic acid was added to the reactor just after inoculation. From then on, an extra portion of $5 \mathrm{~g}$ petroselinic acid was added every $24 \mathrm{~h}$. The initial $\mathrm{pH}$ of 5.8 was allowed to drop spontaneously till 3.5 and was maintained at this value afterwards by automated addition of a $5 \mathrm{~N} \mathrm{NaOH}$ solution. Additional glucose was added $147 \mathrm{~h}$ after inoculation. The stirring rate was set at $600 \mathrm{rpm}$ just after inoculation. After $18 \mathrm{~h}$, the stirring rate was raised to $700 \mathrm{rpm}$ since the dissolved oxygen $\left(\mathrm{pO}_{2}\right)$ dropped to $3 \%$. After $163 \mathrm{~h}$, the stirring rate was raised once more to $800 \mathrm{rpm}$ since the produced sophorolipid lactones formed a highly viscous broth. Growth of the culture was frequently monitored by measuring optical density at $600 \mathrm{~nm}$ (Jasco, V-630 Bio Spectrophotometer). Cell dry weight was obtained by centrifugation ( $5 \mathrm{~min}, 14000 \mathrm{rpm}$, Sigma 4-15 centrifuge) of $1 \mathrm{~mL}$ reactor broth in pre-dried and weighed falcons. The pellets were subsequently washed once with $1 \mathrm{~mL}$ physiological solution $(9 \mathrm{~g} / \mathrm{L} \mathrm{NaCl})$ and dried at $60{ }^{\circ} \mathrm{C}$ to a constant weight. Glucose concentrations were measured with a 2700 Select Biochemistry Analyzer (YSI). 


\section{Sophorolipid purification}

The fermentation broth was transferred to a $2 \mathrm{~L}$ flask and the culture vessel was rinsed with $500 \mathrm{~mL}$ water which was also collected. The fermentation broth was kept overnight at $50{ }^{\circ} \mathrm{C}$ to induce precipitation of the sophorolipid lactones. Afterwards, the upper water layer which contains the yeast cells was removed, filtered over a Whatman filter and once more kept overnight at $50{ }^{\circ} \mathrm{C}$ to induce precipitation of residual sophorolipid lactones. The sophorolipid fraction was resuspended in water, transferred to a $2 \mathrm{~L}$ erlenmeyer and shaken overnight at $4{ }^{\circ} \mathrm{C}$ to induce crystallization of the sophorolipid lactones. However, crystallization did not occur as is the case for oleic acid based sophorolipid lactones. Therefore, the dense sophorolipid phase was separated from the water phase, dissolved in ethyl acetate and washed with an aqueous sodium bicarbonate solution. The ethyl acetate phase was dried over magnesium sulfate and concentrated under reduced pressure. The water phase was also extracted with ethyl acetate, washed with sodium bicarbonate, dried over magnesium sulfate and concentrated under reduced pressure (Additional file 1: Figs. S3, S4).

\section{General procedure for the synthesis of sophorolipid acid 7}

In a $100 \mathrm{~mL}$ round-bottomed flask, $1.01 \mathrm{~g}$ lactonic SL $\mathbf{5}$ $(1.47 \mathrm{mmol}, 1 \mathrm{eq})$ was dissolved in aqueous $3 \mathrm{~N} \mathrm{NaOH}$ and refluxed for $20 \mathrm{~min}$. The reaction mixture was cooled down and acidified with concentrated $\mathrm{HCl}$ to $\mathrm{pH} 5$ to induce precipitation of sophorolipid acid 7 as a white powder. The precipitate was filtered, washed with water and dried under reduced pressure $(0.87 \mathrm{~g}$, yield $95 \%)$ (Additional file 1: Figs. S5, S6).

\section{Surface tension measurements}

The determination of the surface tension was performed at room temperature via the Wilhelmy plate method. All glassware and the platinum plate were rinsed with sulfochromic acid prior to the experiment to avoid interference of traces of residual compounds. A dilution series in distilled water ranging from $2.0 \mathrm{~g} / \mathrm{L}$ to $0.01 \mathrm{mg} / \mathrm{L}$ was prepared and the surface tension was determined for each sample. The CMC values were determined as the concentration at which the minimal surface tension was reached when plotting the natural logarithm of the sophorolipid concentration against the surface tension. For sophorolipid lactone 5, the concentration of solubilized sophorolipid was determined with the TOC-5000 (Shimadzu) since this compound is not well soluble in water. With the bruto formula $\left(\mathrm{C}_{34} \mathrm{H}_{56} \mathrm{O}_{14}\right)$, the actual sophorolipid concentration could be calculated.

\section{General procedure for the synthesis of sophorolipid methyl} ester 8

In a $100 \mathrm{~mL}$ flame dried round-bottomed flask, sodium methoxide was formed in situ by addition of $0.05 \mathrm{~g}$ sodium ( $2.05 \mathrm{mmol}, 0.15 \mathrm{eq})$ to $20 \mathrm{~mL}$ dry methanol and $9.39 \mathrm{~g}$ lactonic SL 5 (13.64 mmol, 1 eq) was subsequently added. The flask was equipped with a reflux condenser and $\mathrm{CaCl}_{2}$ guard-tube to protect the reaction mixture from atmospheric moisture. The reaction mixture was stirred for $3 \mathrm{~h}$ at reflux temperature, cooled down to room temperature and acidified to neutral $\mathrm{pH}$ with acetic acid. The mixture was concentrated under reduced pressure, dissolved in deionized water and cooled down to $0{ }^{\circ} \mathrm{C}$ in an ice bath. The sophorolipid methyl ester 8 precipitated as a white powder. The precipitate was filtered, washed with water and dried under reduced pressure (7.81 g, yield $90 \%$ ) (Additional file 1: Figs. S7, S8).

\section{General procedure for the synthesis of peracetylated sophorolipid methyl ester 9}

In a $100 \mathrm{~mL}$ flame dried round-bottomed flask, $5.59 \mathrm{~g}$ sophorolipid methyl ester 8 ( $8.78 \mathrm{mmol}, 1 \mathrm{eq})$ was dissolved in $50 \mathrm{~mL}$ dry THF. The flask was equipped with a $\mathrm{CaCl}_{2}$ guard-tube to protect the reaction mixture from atmospheric moisture and $5.93 \mathrm{~mL}$ acetic anhydride $(61.87 \mathrm{mmol}, 7.05 \mathrm{eq})$ and $0.43 \mathrm{~g}$ DMAP $(3.51 \mathrm{mmol}$, $0.4 \mathrm{eq})$ were added. The reaction mixture was stirred for $1 \mathrm{~h}$ at room temperature, concentrated under reduced pressure and dissolved in ethyl acetate. The mixture was washed 3 times with a $10 \mathrm{~mL}$ saturated $\mathrm{NaHCO}_{3}$-solution and the organic phase was dried over $\mathrm{MgSO}_{4}$, filtered and concentrated under reduced pressure. Peracetylated sophorolipid methyl ester 9 was isolated as a viscous colourless oil (8.17 g, quantitative yield) (Additional file 1: Figs. S9, S10).

\section{General procedure for the synthesis of sophorolipid aldehyde 4}

In a $250 \mathrm{~mL}$ washing flask, $1.00 \mathrm{~g}$ peracetylated sophorolipid methyl ester $(1.07 \mathrm{mmol}, 1 \mathrm{eq}) 9$ was dissolved in $50 \mathrm{~mL} \mathrm{MeOH} .0 .09 \mathrm{~g} \mathrm{NaHCO}_{3}(1.07 \mathrm{mmol}$, $1 \mathrm{eq})$ and a pinch of Sudan III indicator were added. The reaction mixture was sparged with ozone at room temperature until the red color of the reaction mixture dissipated. After addition of $0.23 \mathrm{~g} \mathrm{NaBH}(\mathrm{OAc})_{3}(1.07 \mathrm{mmol}$, 
$1 \mathrm{eq}$ ), the mixture was stirred for $1 \mathrm{~h}$ at room temperature, concentrated under reduced pressure and dissolved in ethyl acetate. The mixture was washed 3 times with $10 \mathrm{~mL}$ brine and the organic phase was dried over $\mathrm{MgSO}_{4}$, filtered and concentrated under reduced pressure. Peracetylated sophorolipid aldehyde $\mathbf{4}$ was purified by automated column chromatography as a viscous colourless oil with a hexane/diethyl ether mixture as eluent $(0.60 \mathrm{~g}$, $60 \%$ ) (Additional file 1: Figs. S11, S12). Gradient: $2 \mathrm{CV}$ $20 \% \mathrm{Et}_{2} \mathrm{O}, 10 \mathrm{CV} 20-100 \% \mathrm{Et}_{2} \mathrm{O}, 9 \mathrm{CV} 100 \% \mathrm{Et}_{2} \mathrm{O}$.

\section{Results}

\section{Purification of petroselinic acid}

The identification of the different fatty acids and their distribution in the vegetable oil was determined via gas chromatography analysis of the fatty acid methyl esters (Table 1). Petroselinic acid is clearly the major fatty acid, constituting $73.3 \%$ of all fatty acids. Linoleic acid and oleic acid are present in a lower amount, respectively 13.9 and $5 \%$ of all fatty acids. The triglycerides from the vegetable oil were hydrolyzed into glycerol and a fatty acid mixture via an alkaline hydrolysis with sodium hydroxide (Scheme 4). Petroselinic acid 1 was isolated from the reaction mixture via crystallization

Table 1 Fatty acid composition (\%) of the vegetable oil of Coriandrium sativum fruits

\begin{tabular}{lc}
\hline Fatty acid & Content (\%) \\
\hline Palmitic acid (C16:0) & 3.2 \\
Palmitoleic acid (C16:1) & 0.2 \\
Stearic acid (C18:0) & 0.8 \\
Petroselinic acid (C18:1n-12) & 72.3 \\
Oleic acid (C18:1n-9) & 5.9 \\
cis-Vaccenic acid (C18:1n-7) & 1.3 \\
Linoleic acid (C18:2) & 13.3 \\
Linolenic acid (C18:3) & 0.2 \\
Arachidic acid (C20:0) & 0.1 \\
SFA & 4.1 \\
MUFA & 79.7 \\
PUFA & 13.5 \\
Identified fatty acids & 97.3 \\
\hline
\end{tabular}

SFA saturated fatty acid, MUFA monounsaturated fatty acid, PUFA polyunsaturated fatty acid, n.d. not detected in absolute ethanol. A high yield of $80 \%$ was obtained, based on the amount of petroselinic acid $\mathbf{1}$ present in the vegetable oil.

\section{Production and characterization of petroselinic acid based sophorolipids}

Petroselinic acid $\mathbf{1}$ was then used as substrate for microbial sophorolipid production (Fig. 1). After the downstream processing, a total amount of $44 \mathrm{~g}$ was obtained as a white powder from the combined ethyl acetate fractions (Fig. 2). This corresponds to a total production of $40 \mathrm{~g} / \mathrm{L}$. Incorporation of de novo synthesized fatty acids such as oleic acid was not observed via NMR-analysis. Comparison of oleic acid based sophorolipid lactone 2 and petroselinic acid based sophorolipid lactone $\mathbf{5}$ via ${ }^{13} \mathrm{C}$-NMR clearly demonstrates the difference between the two sophorolipid compounds (Fig. 3). Diacetylated sophorolipid lactone $\mathbf{5}$ was subsequently subjected to alkaline hydrolysis with $\mathrm{NaOH}$ to yield petroselinic acid based sophorolipid acid 7 (Scheme 5).

For both petroselinic acid based sophorolipid compounds, the CMC value and the corresponding surface tension were determined and compared to their oleic acid based counterparts (Table 2). Much lower CMC values are obtained for the petroselinic acid based sophorolipids compared to their oleic acid based counterparts (Roelants et al. 2015). However, the minimal surface tension at these CMC values is almost the same. A less compact geometry for the petroselinic acid based sophorolipids could explain their higher CMC values compared to their oleic acid based counterparts. The increasing hydrophobicity for petroselinic acid based sophorolipid lactone $\mathbf{5}$ compared to petroselinic acid based sophorolipid acid 7 resulted in a decreasing $\mathrm{CMC}$ value, as was the case for their oleic acid based counterparts.

\section{Chemical modification towards a C12 sophorolipid aldehyde}

Diacetylated sophorolipid lactone $\mathbf{5}$ was used for the synthesis of mid-chain sophorolipid aldehyde 4 (Scheme 6). A chemical modification pathway towards sophorolipid aldehydes starting from the microbially produced sophorolipid lactones was already developed in our laboratory for oleic acid derived sophorolipids (Delbeke et al.

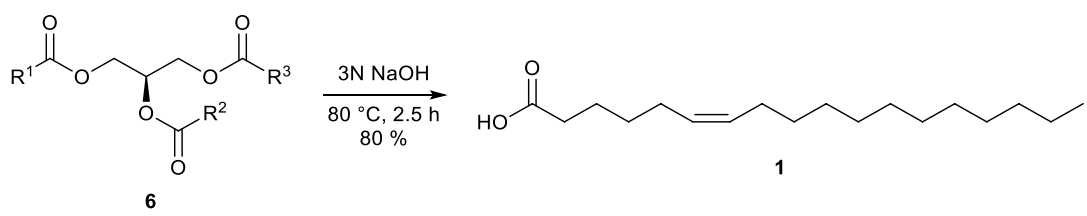

Scheme 4 Alkaline hydrolysis towards petroselinic acid 


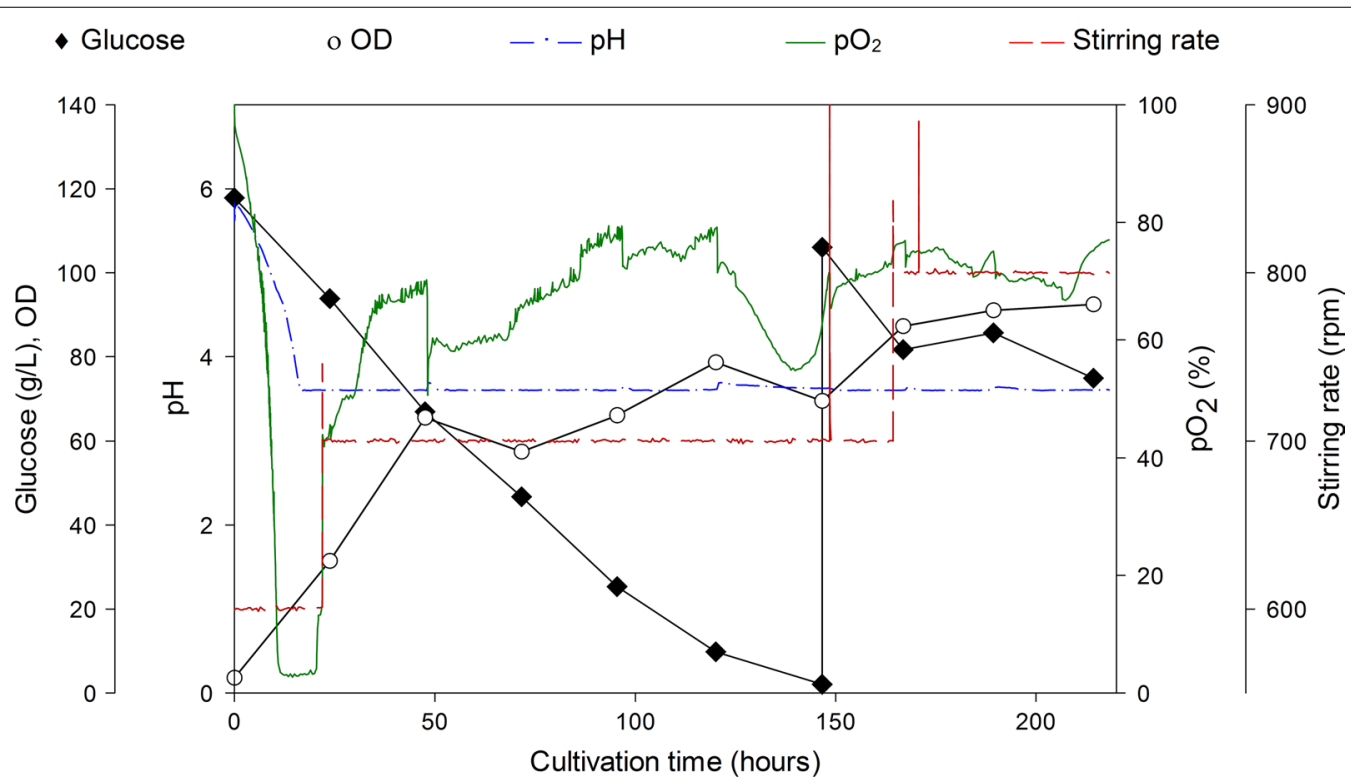

Fig. 1 Sophorolipid fermentation parameters depicted in function of time

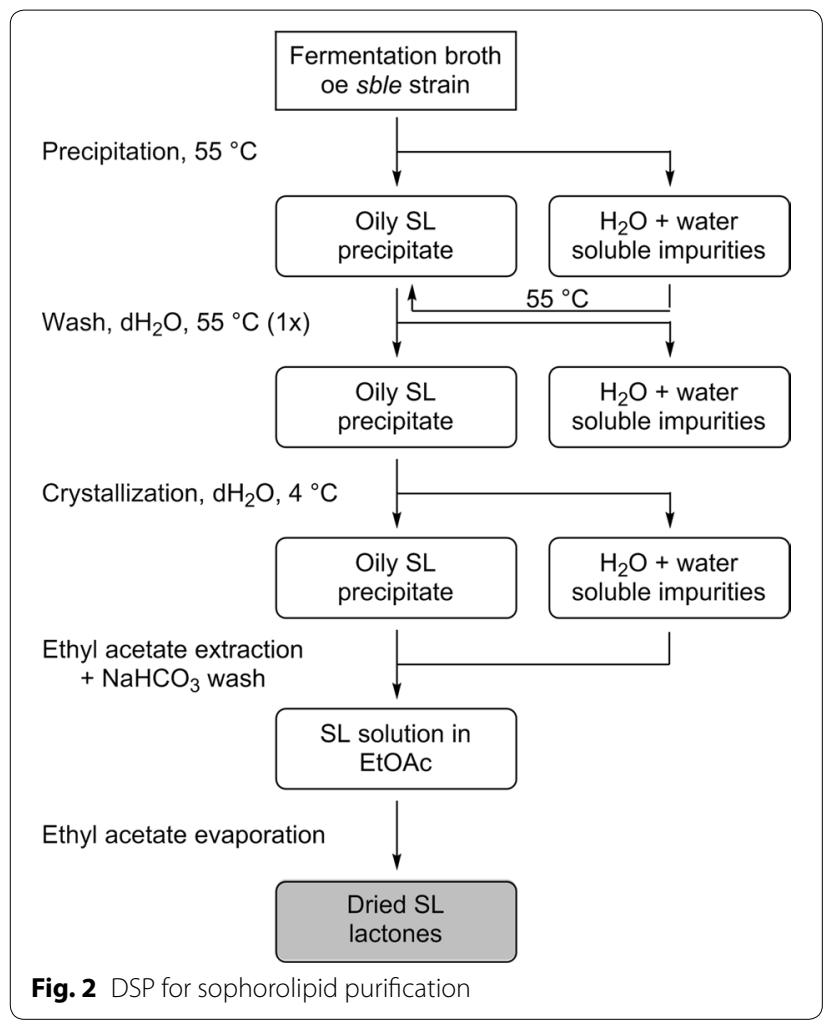

2015). In a first step, sophorolipid lactone 5 was transformed into sophorolipid methyl ester $\mathbf{8}$ via an alkaline hydrolysis with sodium methoxide in methanol. Protection of the sugar head group via an acetylation reaction yielded peracetylated sophorolipid methyl ester $\mathbf{9}$. Cleavage of the double bond was obtained via an ozonolysis reaction, resulting in the synthesis of sophorolipid aldehyde 4.

\section{Discussion}

Different hydrophobic substrates other than oleic acid have already been reported for sophorolipid fermentation, for example hydroxylated fatty acids (Van Bogaert et al. 2011b), arachidonic acid (Prabhune et al. 2002; Shah and Prabhune 2007; Van Bogaert et al. 2009), linoleic acid (Kasture et al. 2008) and linolenic acid (Gupta and Prabhune 2012). In this work, a synthetic pathway towards new-to-nature sophorolipids was developed via the incorporation of petroselinic acid $\mathbf{1}$ in the fermentation pathway. Incorporation of petroselinic acid in sophorolipid derivatives was never described before and offers many advantages. First of all, high amounts of petroselinic acid $\mathbf{1}$ are present in the vegetable oil of C. sativum fruits, making this fatty acid economically interesting as hydrophobic substrate for sophorolipid 


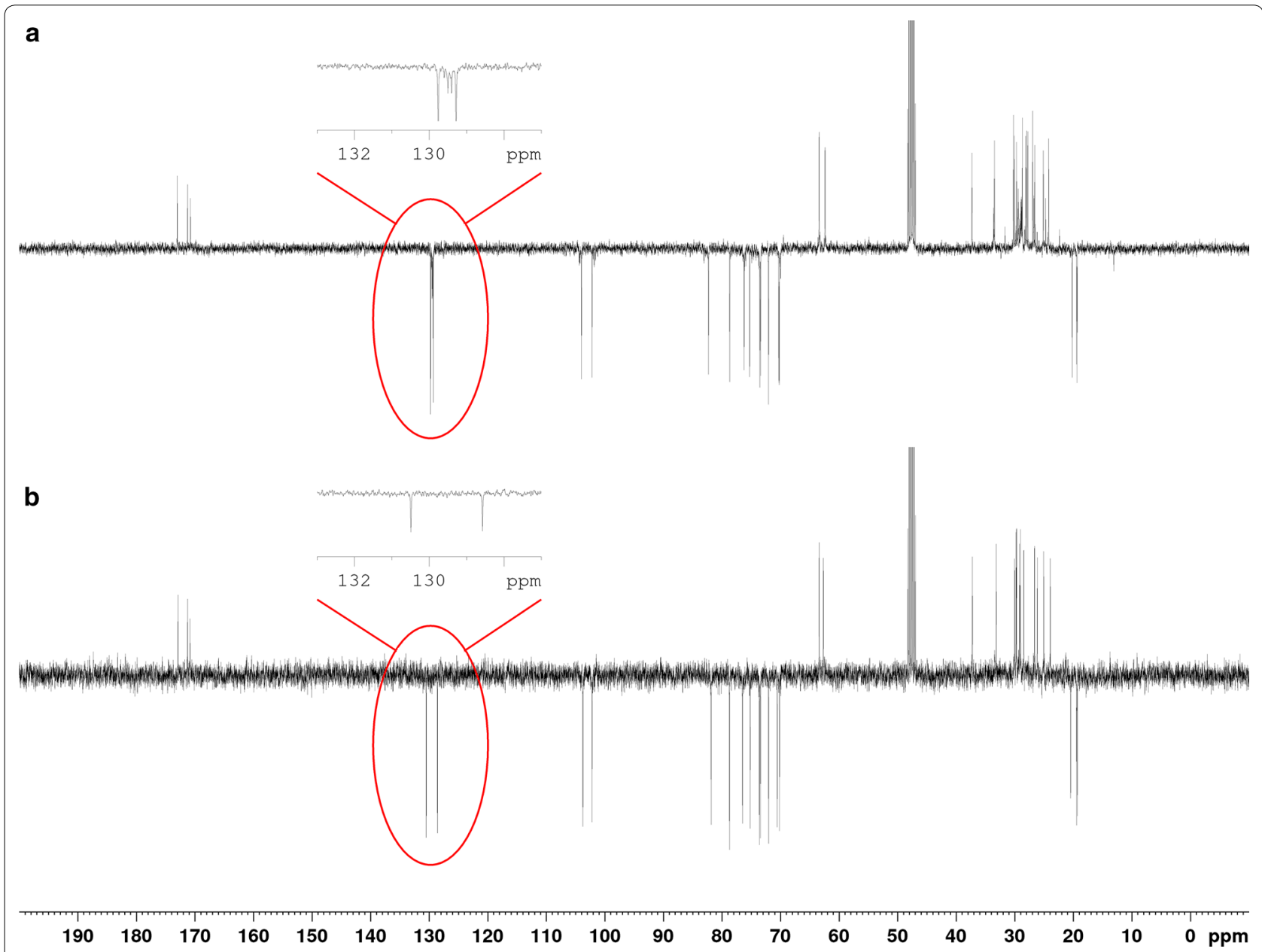

Fig. 3 Comparison of sophorolipid lactones by ${ }^{13} \mathrm{C}-\mathrm{NMR}$. a Oleic acid based sophorolipid lactone, $\mathbf{b}$ petroselinic acid based sophorolipid lactone
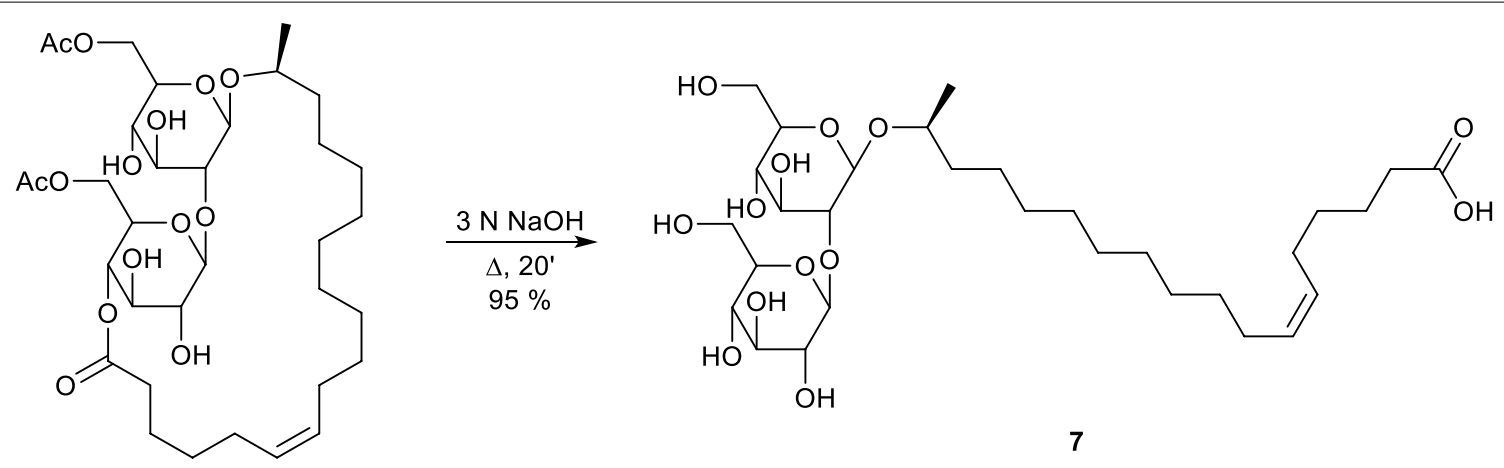

5

Scheme 5 Alkaline hydrolysis towards petroselinic acid based sophorolipid acid $\mathbf{7}$

fermentation. Furthermore, the position of the double bond of petroselinic acid $\mathbf{1}$ greatly influences the characteristics of this fatty acid as compared to oleic acid. Therefore, it is anticipated that incorporation of petroselinic acid in sophorolipid compounds can also have a great influence on the sophorolipid properties. Besides, synthesis of sophorolipid compounds with the double bond at an alternative position opens possibilities for the synthesis of mid-chain $\mathrm{C} 12$ sophorolipid derivatives via an ozonolysis reaction. 
Table 2 Comparison of CMC value and corresponding surface tension for petroselinic acid (PA) and oleic acid (OA) based sophorolipid compounds

\begin{tabular}{lcl}
\hline & CMC $(\mathbf{m g} / \mathbf{L})$ & Surface tension $(\mathbf{m N} / \mathbf{m})$ \\
\hline PA SL lactone & $4.2 \pm 0.1$ & $34.3 \pm 0.0$ \\
OA SL lactone & $45.1 \pm 0.1$ & $33.9 \pm 0.7$ \\
PA SL acid & $154 \pm 5$ & $42.0 \pm 0.3$ \\
OA SL acid & $245 \pm 9$ & $40.9 \pm 0.3$ \\
\hline
\end{tabular}

The data for the OA based sophorolipid compounds were previously determined by Roelants et al. (2015)

Petroselinic acid $\mathbf{1}$ was isolated from the vegetable oil of C. sativum fruits via twin-screw extrusion and alkaline hydrolysis in a high yield of $80 \%$ and was subsequently used as substrate for sophorolipid fermentation with a $S$. bombicola lactone esterase overexpression strain (oe sble). This modified strain only produces sophorolipid lactones, thus resulting in a more homogenous sophorolipid product than the one that can be obtained with the S. bombicola wild type. The desired sophorolipid lactone 5 was obtained in high purity without incorporation of de novo synthesized fatty acids. The corresponding petroselinic acid based sophorolipid acid 7 was synthesized from sophorolipid lactone 5 via alkaline hydrolysis. Petroselinic acid based sophorolipid lactone 5 and acid 7 have a much lower CMC value than their oleic acid based counterparts, which indicates that the fatty acid incorporated in the sophorolipid has a great influence on the geometric structure of the derivatives. The sophorolipid fermentation product was chemically modified towards $\mathrm{C} 12$ sophorolipid aldehyde 4. This derivative constitutes an interesting building block for further modification towards new-to-nature sophorolipids with high potential for self-assembly applications. Similar modifications as those described for oleic acid based sophorolipids are currently in progress (Delbeke et al. 2015).

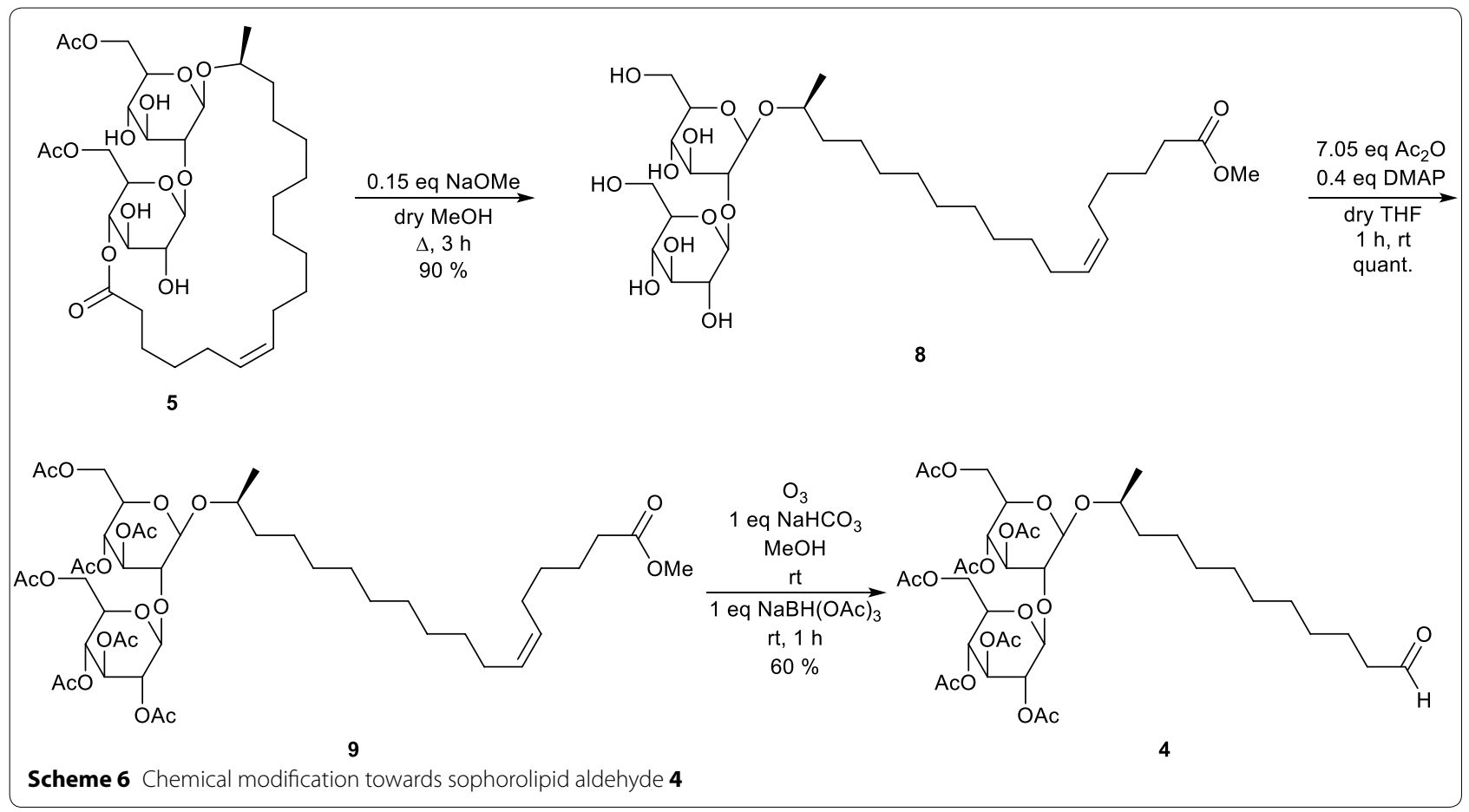




\section{Additional file}

Additional file 1: Fig. S1. ${ }^{1} H-N M R$ spectrum for compound 1. Fig. $\mathbf{S 2}$. ${ }^{13} \mathrm{C}-\mathrm{NMR}$ spectrum for compound $\mathbf{1}$. Fig. S3. ${ }^{1} \mathrm{H}-\mathrm{NMR}$ spectrum for compound 5. Fig. S4. ${ }^{13} \mathrm{C}-\mathrm{NMR}$ spectrum for compound $\mathbf{5}$. Fig. S5. ${ }^{1} \mathrm{H}-\mathrm{NMR}$ spectrum for compound $\mathbf{7}$. Fig. $\mathbf{S 6} .{ }^{13} \mathrm{C}-\mathrm{NMR}$ spectrum for compound $\mathbf{7}$. Fig. S7. ${ }^{1} \mathrm{H}-\mathrm{NMR}$ spectrum for compound $\mathbf{8}$. Fig. $\mathbf{\text { S8}} .{ }^{13} \mathrm{C}-\mathrm{NMR}$ spectrum for compound 8. Fig. S9. ${ }^{1} H-N M R$ spectrum for compound $\mathbf{9}$. Fig. S10. ${ }^{13} \mathrm{C}-\mathrm{NMR}$ spectrum for compound $\mathbf{9}$. Fig. S11. ${ }^{1} \mathrm{H}-\mathrm{NMR}$ spectrum for compound 4. Fig. S12. ${ }^{13} \mathrm{C}-\mathrm{NMR}$ spectrum for compound $\mathbf{4}$.

\section{Authors' contributions}

EU determined the fatty acid composition of the coriander oil. EIPD, JE, EU and AV participated in the purification of petroselinic acid. JE and SV carried out the sophorolipid fermentation. EIPD and JE participated in the chemical modification of the petroselinic acid based sophorolipids. EIPD performed the surface tension measurements and drafted the manuscript. TT, WS, INAVB and CVS contributed in coordination, generation of the grant money and manuscript revision. All authors read and approved the final manuscript.

\section{Author details}

1 SynBioC, Department of Sustainable Organic Chemistry and Technology, Ghent University, Coupure Links 653, 9000 Ghent, Belgium. ${ }^{2}$ InBio, Department of Biochemical and Microbial Technology, Ghent University, Coupure Links 653, 9000 Ghent, Belgium. ${ }^{3}$ Laboratoire de Chimie Agro-industrielle, ENSIACET, Université de Toulouse, INP, 4 Allée Emile Monso, BP 44362, 31030 Toulouse Cedex 4, France.

\section{Acknowledgements}

The authors gratefully acknowledge LCA (Toulouse, France) for the delivery of the coriander vegetable oil, and the Particle and Interfacial Technology Group (Department of Applied Analytical and Physical Chemistry, Ghent University, Belgium) for their help with the determination of the CMC values.

\section{Competing interests}

The authors declare that they have no competing interests.

\section{Human and animal rights statement}

This article does not contain any studies with human participants or animals performed by any of the authors.

Received: 24 February 2016 Accepted: 22 March 2016

Published online: 31 March 2016

\section{References}

Alaluf S, Hu H-L, Green MR, Powell JR, Rawlings AV, Rogers JS, Watkinson A, Cain FW. Cosmetic use of petroselinic acid. EP. 1999;1 (013):178.

Baccile N, Babonneau F, Jestin J, Pehau-Arnaudet G, Van Bogaert I. Unusual, $\mathrm{pH}$-induced, self-assembly of sophorolipid biosurfactants. ACS Nano. 2012;6:4763-76. doi:10.1021/nn204911k.

Baccile N, Nassif N, Malfatti L, Van Bogaert INA, Soetaert W, Pehau-Arnaudet G, Babonneau F. Sophorolipids: a yeast-derived glycolipid as greener structure directing agents for self-assembled nanomaterials. Green Chem. 2010;12:1564-7. doi:10.1039/C0gc00163e.

Baccile N, Pedersen JS, Pehau-Arnaudet G, Van Bogaert INA. Surface charge of acidic sophorolipid micelles: effect of base and time. Soft Matter. 2013;9:4911-22. doi:10.1039/c3sm50160d.

Barrett KE, Green MR, Hu H-L, Parmar P, Powell JR, Rawlings AV. Skin care composition. US Pat. 2000;6(455):057.

Cahoon EB, Dormann P, Ohlrogge JB. Petroselinic acid biosynthesis and production in transgenic plants. Prog Lipis Res. 1994;33:155-63. doi:10.1016/0163-7827(94)90018-3.

Cuvier AS, Babonneau F, Berton J, Stevens CV, Fadda GC, Genois I, Le Griel P, Pehau-Arnaudet G, Baccile N. Synthesis of uniform, monodisperse, sophorolipid twisted ribbons. Chem Asian J. 2015;10:2419-26. doi:10.1002/asia.201500693.
Cuvier AS, Berton J, Stevens CV, Fadda GC, Babonneau F, Van Bogaert INA, Soetaert W, Pehau-Arnaudet G, Baccile N. pH-triggered formation of nanoribbons from yeast-derived glycolipid biosurfactants. Soft Matter. 2014;10:3950-9. doi:10.1039/C4sm00111g.

Delbeke EIP, Movsisyan M, Van Geem KM, Stevens CV. Chemical and enzymatic modification of sophorolipids. Green Chem. 2016;18:76-104. doi:10.1039/ C5GC02187A.

Delbeke EIP, Roman BI, Marin GB, Van Geem KM, Stevens CV. A new class of antimicrobial biosurfactants: quaternary ammonium sophorolipids. Green Chem. 2015;17:3373-7. doi:10.1039/c5gc00120j.

Dierker M, Schafer HJ. Surfactants from oleic, erucic and petroselinic acid: synthesis and properties. Eur J Lipid Sci Technol. 2010;112:122-36. doi:10.1002/ejlt.200900126.

Gupta R, Prabhune AA. Structural determination and chemical esterification of the sophorolipids produced by Candida bombicola grown on glucose and alpha-linolenic acid. Biotechnol Lett. 2012;34:701-7. doi:10.1007/ s10529-011-0818-y.

Heimerma.Wh, Gordon DT, Kowalysh.De, Jensen RG, Holman RT. Effect of double-bond position in octadecenoates upon hydrolysis by pancreatic lipase. Lipids. 1973;8:45-6. doi:10.1007/Bf02533239.

Kasture MB, Patel P, Prabhune AA, Ramana CV, Kulkarni AA, Prasad BLV. Synthesis of silver nanoparticles by sophorolipids: effect of temperature and sophorolipid structure on the size of particles. J Chem Sci. 2008;120:51520. doi:10.1007/s12039-008-0080-6.

Lang S, Brakemeier A, Heckmann R, Spockner S, Rau U. Production of native and modified sophorose lipids. Chim Oggi. 2000;18:76-9.

Morya VK, Ahn C, Jeon S, Kim EK. Medicinal and cosmetic potentials of sophorolipids. Mini Rev Med Chem. 2013;13:1761-8. doi:10.2174/138955 75113139990002

Placek LL. Review on petroselinic acid and its derivativees. J Am Oil Chem Soc. 1963:40:319-29. doi:10.1007/Bf02631548.

Prabhune A, Fox SR, Ratledge C. Transformation of arachidonic acid to 19-hydroxy- and 20-hydroxy-eicosatetraenoic acids using Candida bombicola. Biotechnol Lett. 2002;24:1041-4. doi:10.1023/A:1015662013985.

Roelants SLKW, Ciesielska K, De Maeseneire SL, Everaert B, Denon Q, Moens H, Vanlerberghe B, Van Bogaert INA, Van der Meeren P, De Vreese B, Soetaert W. Towards the industrialisation of new biosurfactants: biotechnological opportunities for the lactone esterase gene from Starmerella bombicola. Biotechnol Bioeng. 2015. doi:10.1002/bit.25815.

Shah S, Prabhune A. Purification by silica gel chromatography using dialysis tubing and characterization of sophorolipids produced from Candida bombicola grown on glucose and arachidonic acid. Biotechnol Lett. 2007;29:267-72. doi:10.1007/s10529-006-9221-5.

Shukla S, Gupta S. Coriander. In: Aggarwal BB, Kunnumakkara AB, editors. Molecular targets and therapeutic uses of spices: modern uses for ancient medicine. Singapore: World Scientific; 2009. p. 149-71.

Uitterhaegen E, Nguyen QH, Sampaio KA, Stevens CV, Merah O, Talou T, Rigal L, Evon P. Extraction of coriander oil using twin-screw extrusion: feasibility study and potential press cake applications. J Am Oil Chem Soc. 2015;92:1219-33. doi:10.1007/s11746-015-2678-4.

Van Bogaert I, Ciesielska K, Devreese B, Soetaert W, Roelants S. A lactonase derived from Candida bombicola and uses thereof. 2011a

Van Bogaert I, Fleurackers S, Van Kerrebroeck S, Develter D, Soetaert W. Production of new-to-nature sophorolipids by cultivating the yeast Candida bombicola on unconventional hydrophobic substrates. Biotechnol Bioeng. 2011 a; 108:734-41. doi:10.1002/bit.23004.

Van Bogaert INA, Sabirova J, Develter D, Soetaert W, Vandamme EJ. Knocking out the MFE-2 gene of Candida bombicola leads to improved medium-chain sophorolipid production. FEMS Yeast Res. 2009;9:610-7. doi:10.1111/j.1567-1364.2009.00501.x.

Van Bogaert INA, Saerens K, De Muynck C, Develter D, Soetaert W, Vandamme EJ. Microbial production and application of sophorolipids. Appl Microbiol Biotechnol. 2007;76:23-34. doi:10.1007/s00253-007-0988-7.

Van Bogaert INA, Zhang JX, Soetaert W. Microbial synthesis of sophorolipids. Process Biochem. 201 1b;46:821-33. doi:10.1016/j.procbio.2011.01.010.

Weber N, Richter KD, Schulte E, Mukherjee KD. Petroselinic acid from dietary triacylglycerols reduces the concentration of arachidonic-acid in tissuelipids of rats. J Nutr. 1995;125:1563-8.

Weinkauf R, Santhanam U, Palanker LR, Januario TG, Brinker A. Petroselinic acid as an anti-irritant in compositions containing alpha hydroxy acids. US Pat. 1998:6(022):896. 